\title{
In memoriam: Professor Hideaki Yamanaka (1940-2019)
}

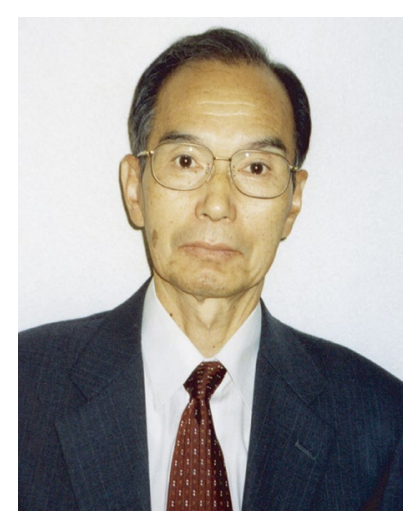

Professor Hideaki Yamanaka, an Honorary Member of the Japanese Society of Fisheries Science, passed away on 5 June 2019 at the age of 79.

Professor Yamanaka was born in Utsunomiya, Japan, on 1 May 1940. He graduated from the Department of Fisheries, Faculty of Agriculture, the University of Tokyo, in March 1964 and completed the Master's Program of the same university in March 1966. After serving as a researcher at Tokai Regional Fisheries Research Laboratory (currently National Research Institute of Fisheries Science, Japan Fisheries Research and Education Agency), he transferred to Tokyo University of Fisheries (currently Tokyo University of Marine Science and Technology) as an assistant professor in 1975 . He was then promoted to the position of associate professor in 1977 and full professor in 1989. Until his retirement in March 2004, he devoted himself to educational and research activities and trained many talented people in various fields.

Professor Yamanaka's research helped to develop a wide range of fishery products related to food storage science and food hygiene chemistry. Apart from mere academic interest, his research also extended to solving problems at fisheries. At Tokai Regional Fisheries Research Laboratory, he found that the orange discoloration of canned skipjack meat is produced by the Maillard reaction of some sugars with nitrogen compounds. This highly acclaimed study granted him the Achievement Award for Young Scientists in Fisheries Science in 1975. After being assigned to Tokyo University of Fisheries, he focused on explaining the postmortem chemical changes in various fish and shellfish. His remarkable achievements improved the quality control of fresh fish and shellfish and greatly contributed to the development of both fisheries science and the fishing industry. He published his research results as a number of articles in domestic and foreign academic journals and summarized them in books and reviews.

Professor Yamanaka served on various committees, and as councilor and supervisor of the society. In recognition of his great contribution to the administration and development of society, and for his research achievements, he was awarded the Japanese Society of Fisheries Science Award of Merit in 2000.

He will be remembered through the many excellent professionals who studied under his tutelage and through his brilliant research achievements. We would like to express our deepest sympathy on the passing of Professor Yamanaka, and extend our sincere condolences to his wife and family.

Kazuo Shiomi

Professor Emeritus,

Tokyo University of Marine Science and Technology

Publisher's Note Springer Nature remains neutral with regard to jurisdictional claims in published maps and institutional affiliations. 